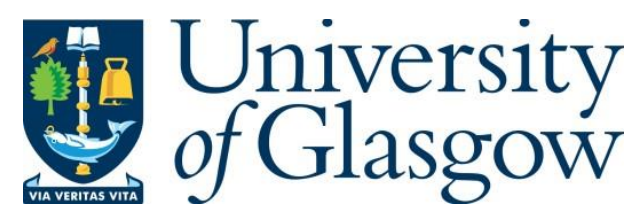

Robinson, P. A. (2019) Farmer and veterinarian attitudes towards the risk of zoonotic Mycobacterium bovis infection in Northern Ireland. Veterinary Record, 185(11), 344.

There may be differences between this version and the published version. You are advised to consult the publisher's version if you wish to cite from it.

http://eprints.gla.ac.uk/201476/

Deposited on: 4 December 2019

Enlighten - Research publications by members of the University of Glasgow http://eprints.gla.ac.uk 
Farmer and veterinarian attitudes towards the risk of zoonotic Mycobacterium bovis infection in Northern Ireland

Philip A. Robinson BVMS DSVM MSc PhD PgCert TSLHE SFHEA MRCVS

Address: Department of Animal Production, Welfare and Veterinary Sciences Harper Adams University

Newport

Shropshire

United Kingdom

TF10 8NB

Email: probinson@harper-adams.ac.uk

Key words: Bovine tuberculosis, Zoonoses, Public Health, Infection

Word count: 5665 
Pre-print accepted version: Veterinary Record - July 2019

\title{
Farmer and veterinarian attitudes towards the risk of zoonotic Mycobacterium bovis infection in Northern Ireland
}

\begin{abstract}
Based on a qualitative social science research methodology using semi-structured interviews, this paper examines the attitudes of farmers and veterinarians in Northern Ireland around the risk of acquiring tuberculosis caused by Mycobacterium bovis (M. bovis) from infected cattle and drinking raw milk. This region has traditionally had one of the highest rates of bovine tuberculosis in the United Kingdom (UK), and amongst the highest in Europe. The research finds that the risk is often downplayed, and considered so rare that it is no longer a significant public health risk due to the pasteurization of milk and intensive surveillance on farms through systematic testing and removal of positive animals, as evidenced by the low recorded human incidence. Although the incidence of tuberculosis in humans caused by $M$. bovis is only around $1 \%$ of all annual human tuberculosis cases, this paper argues that $M$. bovis may be underestimated as a human pathogen, and makes the case for a renewed perspective. Discourses surrounding the disease may need to be reorientated to remind relevant stakeholders that human infection with $M$. bovis is a hazard that needs to be treated with more caution on the frontline of control.
\end{abstract}

\section{Introduction}

It is generally accepted that bovine tuberculosis (bTB) poses a low threat to humans in developed, high-income countries with established bTB surveillance programmes ${ }^{1,2}$. Based on the pasteurization of milk and inspection of bovine carcasses in abattoirs alongside 
intensive tuberculin testing of the cattle population, it is relatively rare to detect Mycobacterium bovis (M. bovis) positive humans. This has led some to argue that the level of investment in cattle control is not justifiable, and that 'bTB control in cattle [in the UK] is irrelevant as a public health policy' ${ }^{3}$. But while the risk of human infection with $M$. bovis may be considered low in developed countries, it is undeniably still present, and for those unfortunate enough to be infected, it can produce a potentially life-threatening disease if not diagnosed early enough and treated aggressively with the appropriate combination of antimicrobials.

Olea-Popelka and others ${ }^{4,5}$ have recently argued that the burden and seriousness of zoonotic tuberculosis in global terms has been underestimated and needs to addressed, but their focus is more on low and middle income countries, where the human risk is higher than in developed countries. This issue has also been highlighted in the 2017 Roadmap for Zoonotic Tuberculosis report published by the World Health Organization (WHO) and others ${ }^{6}$. Much less attention has been directed to developed countries where bTB remains a significant problem in their cattle industries, such as the UK.

It is well recognized in public health research that risk perception of an infectious disease will in turn affect behaviours ${ }^{7}$, and it is likely that attitudes towards a long-established endemic disease will differ from those towards a newly emerging infection ${ }^{8,9}$. Given that bTB has a long history in the UK and remains endemic in cattle, with a correspondingly low incidence in humans, it might be hypothesized that those most exposed to the infection will consider it a low risk to their health. This may in turn (unwittingly) produce risky attitudes and behaviours on bTB-affected farms. To investigate this hypothesis, this paper explores the attitudes and opinions of two groups of stakeholders who are at risk of occupational 
zoonotic $M$. bovis infection and/or involved in providing advice on bTB control - cattle farmers and livestock veterinarians - in Northern Ireland (NI). This region of the UK has had a relatively high cattle incidence of the disease over the past 40 years, and consistently higher than most of the rest of the UK. A statutory eradication programme was initiated in 1959 , and although this was very successful in the following decade ${ }^{10}$, herd incidence has increased to higher levels once again since the mid-1970s, undoing the early programme gains, and causing disillusionment and frustration amongst all stakeholders ${ }^{11}$. With a total cattle population of $1.63 \mathrm{M}$ in $\mathrm{NI}$ in $2018^{12}$, a bTB herd incidence of $9.22 \%$, and an animal

incidence of $0.88 \%$ in the same year ${ }^{13}$, is zoonotic TB from cattle to be feared as an ongoing public health risk, or largely to be ignored?

\section{Materials and method}

As part of a wider qualitative study of the bTB eradication policy in NI, 86 participants were interviewed by the author through a total of 60 semi-structured interviews (involving 78 people, majority one-to-one) and two semi-structured focus groups (involving 8 participants - one farmer group, one veterinarian group) conducted between September 2012 and May 2013. The participants included 47 farmers and 30 veterinarians along with other industry stakeholders and state officials. The participation rate was almost $100 \%$ of those approached. The overall aim of the study was to investigate why bTB had not yet been successfully eradicated from NI. The study received ethical approval from a research ethics committee at Durham University before commencement. The farming interviewees were purposively selected ${ }^{14}$ to provide a range of experiences of bTB (persistent breakdowns, occasional breakdowns, consistently bTB-free) across herd types (dairy and beef) and herd sizes. These were selected through known contacts of the author or through gatekeepers 
such as veterinarians in private veterinary practice, and by farming interviewees suggesting other farmers meeting the sampling criteria. The vast majority were full-time farmers, and they were principally located in two areas of $\mathrm{NI}$ - one a high incidence area for bTB, the other a traditionally low incidence area. All farmer participants were engaged with the bTB eradication programme through presenting their cattle for at least annual statutory herd testing. The private veterinarians $(n=17)$ were all involved in testing cattle as subcontractors for the state, and the state veterinarians $(n=13)$ were involved either in field duties (testing and outbreak investigation, abattoir meat inspection) or policy roles connected to bTB control across NI.

Within the overall sample, the subject of zoonotic infection from M. bovis was discussed during the interview in a subset of 24 interviews that involved 29 interviewees including cattle farmers (both dairy and beef) and private and state veterinarians. In half of the interviews where $M$. bovis was discussed as a zoonosis, the participant was specifically asked about their views on the zoonotic threat (depending on the direction of the discussion), but in the other half of the interviews this subject was first raised by the interviewee in wider discourse about the disease eradication programme. The interviews and focus groups were deliberately semi-structured, and this allowed freedom within the interview to follow themes and issues raised by participants in addition to those asked by the interviewer through prepared questions. No two interviews were therefore exactly the same in structure or content, but typical questions asked in the interviews are shown in Table 1. 


\section{Table 1: Typical questions asked during the semi-structured interviews}

\section{General}

What are the primary reasons for the State trying to control bTB ?

Should the government continue to control or eradicate bTB, or should they give up?

Is there a case for the State pulling back from bTB control?

\section{Farmer}

What is this disease? What do you know about it?

What about the human health threat? Did you think about that? Were you worried?

There are people who drink raw milk. What do you think of that? Would you do that?

Are you worried about getting sick through drinking raw milk?

Would you drink your own milk? You don't have any fears about that?

How much of a zoonotic risk do you think bTB is today?

Do you ever think about the risk of being infected with bTB?

Do you think we're very complacent?

How do you feel when during a breakdown you go out to reactor animals before they leave - are you scared or worried about your own health, or thinking that 'this house is infected' or anything like that?

Have you ever met any older men (sic) who remember when people had TB - back at the time of the war and so on?

Why do you think we don't see many people with TB today?

\section{Veterinary}

Have you ever heard of farmers that you knew developing bTB?

Why do you think farmers are prepared to take the risk of drinking raw milk, no matter what public health advice you give them?

Milk historically was obviously a big issue; do you think it's becoming an issue again?

Some have suggested that $M$. bovis and bTB are not a zoonotic threat today, and we should just give up trying to control it. What do you think of that argument?

How dangerous do you think Mycobacterium bovis is?

Do you think that vets should be worried about this disease in terms of contracting it themselves?

Would you drink unpasteurized milk? What if it was on a bTB reactor farm? 
The individual and focus group interviews were conducted and audio-recorded following informed consent, and were then transcribed verbatim using $f 4$ software (www.audiotranskription.de) before thematic analysis using NVivo 10 software (QSR International Pty Ltd, Australia). This analysis process involved repeatedly reading the transcripts to develop themes and sort the data according to theme and sub-theme. Discussion of bTB as a zoonosis was part of a wider theme around risk framings of the disease from both lay and expert perspectives ${ }^{15}$.

\section{Results}

\section{General awareness of the zoonotic risk}

There was a generally high level of awareness of bTB's zoonotic capabilities amongst interviewees, but opinions varied on the magnitude of that risk in the twenty-first century compared to the past, particularly before pasteurization became widespread in the 1950 s. One farmer who claimed to know nothing about bTB knew that it could potentially affect people, and older farmers and veterinarians remembered conversations in the past about people who had died of tuberculosis. Known historically as consumption, these memories were probably more likely to be based on the human variant of the organism (Mycobacterium tuberculosis) rather than the bovine bacterium:

'There was the old doctors' adage: "Beware of the coughing granny in the corner". Apparently, there was a whole family, and the [grandmother] was coughing ... and within a few years, ten or twelve of that family had died of TB. People forget that.' (Int A49, private veterinarian) 
'It wouldn't be a nice death ... People have talked here and there about people who died with consumption. Hopefully with pasteurization it more or less does away with that.' (Int A53, farmer)

The largely successful elimination of tuberculosis in humans, so that very few members of the public had any direct knowledge of, or connection to, the historical disease, meant a disconnect between past reality and current risk, leading one veterinarian to question whether there was any public health benefit in attempting to control bovine disease:

'The general population doesn't actually recognise TB as being a threat to them at all ... generations have passed since people went into TB hospitals to recover ... If TB did start to move into the general population it would be a different attitude. But at the moment, is the money that's being spent on bTB testing in NI actually reducing any clinical disease in humans?' (Int A50, private veterinarian)

One dairy farmer suggested that while he was aware of the ongoing risk of tuberculosis in humans, he focused on human-to-human transmission of infection from developing countries rather than $M$. bovis infection in the UK:

'The human aspect is still very relevant - and it is not being hammered home to the activists - how on the flight from [Africa], you are more at risk from getting TB from that than from getting bTB in the milk, because the eradication programmes in the sub-continent of Africa haven't really taken place.' (Int A58, farmer)

When asked about whether the state should withdraw from seeking to eradicate bTB in cattle given its very significant financial cost to taxpayers, a state veterinarian predicted what would happen in the future in such a situation: 
'If you took your hands off bTB it would reach some natural level, probably around $25 \%$ animal incidence ... The only people that are probably physically under threat from that are the farmers and the farmer's family, so you can control that threat to a large degree, or at least they take their own risk.' (Int A56, state veterinarian)

Overall, the considerable economic benefits of maintaining an export market for cattle and cattle products through the eradication programme were emphasized by several participants, with the assessment that this had largely eliminated the public health threat, as evidenced by the following quotes:

'[The bTB scheme] allows us an export market, and it was brought in originally to stop TB in humans and so on, and there aren't many people nowadays who get TB.' (Int A52, private veterinarian)

'The zoonotic threat is minimised, as we see from the human surveillance - we only get the odd case in humans. So from a zoonotic point of view it's a no-brainer ... It's very much an economic or trade disease, rather than one of zoonotic potential.' (Int A45, state veterinarian)

\section{Risk from contaminated milk}

The vital contribution of pasteurization in protecting public health was emphasized by the veterinarians. They also tended to underline the ongoing importance of surveillance in cattle through herd testing, alongside the food safety controls such as pasteurization and meat inspection:

'Let's not forget that bTB once upon a time was a very significant public health risk, so although the controls now tend to be through milk pasteurization and other 
things, we are capping the level of disease through intensive surveillance.' (Int A55, state veterinarian)

'In this country human health is not a big problem because pasteurization of milk solves the problem. But if we just based it on pasteurization and did no more [bTB] testing we would have a very, very sick badger population; a very, very sick cattle population; [and] a very, very sick herd keeper population.' (Int A41, state veterinarian)

Attitudes varied on the risk of infection of humans acquiring M.bovis from unpasteurized milk. Veterinarians certainly seemed wary of drinking raw milk, particularly on bTB-infected farms:

Author: 'Would you personally drink unpasteurized milk?'

Vet: 'I have done so on farms. If you get a cup of tea you know they've just taken a scoop from the tank. I have to say it probably doesn't bother me a huge amount, because I think the chances of me getting it through milk are probably pretty slim.'

Author: 'What if it was a bTB-positive farm?'

Vet: 'Oh, I don't think I would - no, no.' (Int A49, private vet)

One private veterinarian suggested that most of his dairy farmer clients no longer drank milk from their own herds (for whatever reason), and this opinion was also confirmed by a farmer who thought that many fewer people were willing to drink it unpasteurized, and that it had become socially unacceptable to supply raw milk to public gatherings: 
'One of the funny things is that farmers are now very aware of drinking their own milk - very aware. I now see a lot of farmhouses that have shop-bought (pasteurized) milk - a lot. And that's a big change.' (Int A50, private vet)

‘Nobody drinks their own milk nowadays - we don't even drink our own milk ... You can't even take it to church functions - years ago, that was [very common] ... Yes, [we stopped] since the grandchildren started coming here - you wouldn't like to give them something which wasn't good for them.' (Int A12, farmer)

State veterinarians warned of the disease potentialities from bTB-infected milk, and one described a large bTB outbreak involving 50 positive dairy calves that had been fed on colostrum and milk from infected cows in the herd. If milk was a vehicle for transmission to other cattle, then the potential for humans on the farm to be infected was also present:

'Some of [the farmers] don't believe you. You try to tell them not to drink the milk ... We had a herd there where at his first test he lost 30 reactors ... Second test he lost 30 reactors ... And the third test he lost 150 reactors, and 50 of them were baby calves that were getting colostrum and 1 in 10 dilutions of the milk.' (Int A43, state veterinarian)

State veterinarians hoped that the majority of farmers would heed their public health advice to avoid drinking raw milk during bTB breakdowns.Yet despite the potential risk, not everyone believed that $M$. bovis was a zoonotic threat in milk, and some farmers chose to ignore the public health advice. Illustrative of this point, one farmer talked about how he and his family continued to drink unpasteurized milk despite a herd test which revealed 70 bTB-positive from 200 dairy cows on their farm. He expressed confidence and pride in the 
quality of the product his farm produced, and that pride in the product appeared to supersede all other considerations:

'I didn't stop drinking the milk. I didn't look at it as a risk - I mean the children ... we all drink the milk. But I think if you are on the milk and you are reared on the milk I can't see what harm it will do you. I have great pride in my milk - I'm always getting in the good bands for hygiene and TBC (total bacterial count) and [somatic] cell count ... and if I can't drink my own milk I wouldn't want to be selling it to anybody.' (Int A8, farmer)

Milk, even if it circulated on a heavily bTB-infected farm, could therefore be viewed by this farmer as a wholesome food product. A few of the other farmer interviewees felt similarly, and drank their milk with no qualms or fears of disease, although they tended not to have a history of bTB on their farm. In fact, they argued that those who did not drink unpasteurized milk were storing up trouble for themselves in not building up resistance to infection in the future, and that pasteurization was an unnecessary form of over-purification:

‘I drink non-pasteurized milk and I have absolutely no issue about it. I think that we are so conscious about germs and diseases that part of the problem is there is no resistance ... everything has been so purified.' (Int A16, farmer)

'Pasteurized and homogenized - I don't like either of those processes. If you think about it logically, if you pasteurize milk you kill all the natural bacteria that are in the milk, so to me there is a big space left there for unnatural bacteria to get in ... I have people coming to the farm looking for raw milk [and] I know that people will pay for a quality product.' (Int A18, organic farmer) 
Veterinarians spoke disapprovingly of such opinions, particularly on bTB-infected farms, as 'macho' attitudes borne through lack of education and underestimation of the risk:

'I think the [reason] is stupidity, and ... complacency. You get used to something, it's there every day. They take a jug of milk in every morning and evening for their family: "It didn't do me any harm, because I'm still alive".' (Int A41, state veterinarian)

'It may well be a Superman kind of attitude - until you actually encounter disease you think you're never going to get ill! Again, there's a need for more education - it could take only one bacillus to get through and they're infected.' (Int A49, private veterinarian)

'Me personally, I wouldn't drink it, but maybe the farmer thinks ... sometimes it's almost a daredevil thing. They don't do things because it's logical [Laughs]' (Int A51, private veterinarian).

\section{Anything to fear?}

In addition to the risk from milk, there is also a potential occupational risk from inhalation of M. bovis aerosols or from other contact with infectious animals or a contaminated environment on the farm. With dairy farmers working daily with their cattle in confined conditions, especially in milking parlours, there is a theoretical risk of inhaling the bacteria expunged in the expirations of diseased animals with open lesions of the lung. Similarly, veterinarians who test cattle often encounter bTB reactor animals, and it would seem likely they are regularly immunologically-challenged by the bacteria in the course of their daily 
work. In these cases BCG vaccine was regarded to be protective by both farmers and veterinarians:

'I wonder if I haven't got TB myself seeing as I'm up-close-and-personal with these animals all the time. Of course, I'm vaccinated - that's a foolish one - strike that.' (Int A19, private vet)

'We're complacent because we have all been given the BCG when we were kids. Now we all know that BCG is not $100 \%$ effective either. Considering how much bTB we have in this country compared to the human version, the number of cases of $M$. bovis in humans is so small. So either our BCG vaccination is working very well for vets and farmers, or for some reason we are not being infected.' (Int A47, state veterinarian)

A dairy farmer who spoke of recurring episodes of bTB in his 500-cow herd had little thought or fear of acquiring zoonotic infection, partly because it was an ever-present, but also because he lacked faith in the diagnostic test in cattle, and believed that his BCG provided adequate cover:

Author: 'How do you feel during a breakdown when you go out to reactor animals before they leave [the farm]? Are you scared, or worried about your own health, or thinking that this house is infected or anything like that?'

Farmer: 'Not really - it's so common. A lot of the time we have animals going away and they don't have the disease, but they had a high reading at a test. No, you just get used to it, and I've got my TB vaccination.' (Int A50, farmer) 
A few of the other state veterinarians also thought that BCG in childhood had produced some degree of complacency about bTB in humans. However, milk pasteurization, better diets and better living conditions were believed to afford protection against disease for most people. One farmer cited his father's belief that historical exposure to M. bovisinfected cattle actually offered protection in lieu of the BCG:

'My father always tells the story that when he had the 6-pins (Mantoux) test [in the 1960s], because the herd was riddled with TB, he [reacted] really strongly - he didn't need the BCG.' (Int A58, farmer)

Two state veterinarians did express concern for the unvaccinated children living on cattle farms in bTB-affected areas, with one expressing his surprise that UK health policy meant that all children were no longer routinely vaccinated with BCG, classifying this as a 'human experiment' which could have serious consequences for public health in the future (Int A47).

Both the statistical and anecdotal evidence would appear to substantiate the expressed views that there was a low risk of clinical disease in humans caused by $M$. bovis in NI. When asked, veterinarians could not think of anyone that they knew of who had acquired TB during their professional careers, except for one whose farm client had been immunocompromised during a large bTB breakdown with over 100 positive animals on his farm. An experienced state veterinarian said that he had never seen a farmer worried about their own health during a bTB breakdown, and a private veterinarian seemed to echo the views of his farming peers:

Author: 'How much of a zoonotic risk do you think bTB is today?'

Vet: (Long pause) 'Small ... it's still there.' 
Author: 'Do you ever think about it?'

Vet: 'Being honest, no.' (Int A39, private vet)

Author: 'What do you think about the human health threat of bTB?'

Farmer: 'I don't think there would be a really big threat from [bTB], because all milk is pasteurized.' (Int A12, farmer)

In general therefore, bTB was not feared as a zoonosis, or as harmful, and was generally regarded to be low risk by both the farmers and veterinarians interviewed. Given that milk was pasteurized and reactor animals could enter the food chain if carcass lesions were localized, a beef farmer questioned the point of the eradication programme: 'What's the whole thing about?' (Int A38). Such sentiments may be the result of the success of the programme in dramatically reducing obvious clinical cases of bTB in cattle, and rendering bTB 'invisible' to farmers apart from what was revealed through tuberculin testing:

'They're not seeing any clinical signs of it ... because we have been controlling it so well, and there are no clinical signs in cattle and no spread to humans, I don't think it's real to them.' (Int A59, private veterinarian)

Author: 'Have you ever seen farmers seriously worried for their own health on a bTB breakdown farm?'

Vet: 'No - they are totally complacent. They have been living with it for so long ... It's there and it hasn't changed ... and the only thing that annoys them is the extra testing, but not the disease.' (Int A41, state veterinarian) 
Indeed the success of reducing bTB to lower levels than historically, and the benefits of intensive surveillance in greatly reducing the risk of emaciated, coughing cattle being present on farms led one veterinarian to confidently declare:

'I don't agree with people who say we aren't any further forward - we are a lot

further forward than we were 50 years ago. We've got to the position now where bTB is no longer a public health issue.' (Int A61, state veterinarian)

\section{Discussion}

According to scientific discourse, and beyond scientific dispute, bTB is a zoonosis, and therefore has the potential to harm humans. Indeed, bTB control programmes in various parts of the world were first instituted to reduce this risk to humans. Historically, $M$. bovis infection fairly commonly affected humans in $\mathrm{NI}$, especially through ingestion of unpasteurized milk, but by 1950 there had been a marked decline due to milk pasteurization and increased efforts to remove tuberculous cattle from farms ${ }^{16}$. If success is measured in absence of clinical disease in humans, it appears to have been successful. Only 36 human cases of M. bovis infection were reported in NI between 1999 and $2017^{17}$, and in $\mathrm{NI}$ in 2016, just 3 cases of $M$. bovis were confirmed by culture from 55 human isolates, the remaining 52 found to be $M$. tuberculosis ${ }^{18}$. The data obtained from the interviews with this particular sample of industry stakeholders demonstrates while there is general acceptance of the potential for zoonotic infection, this is largely viewed as a relic of history, and one which is seldom considered in the course of daily life and labour on the farm. Veterinarians, as would be expected from healthcare professionals trained in veterinary public health, are more aware of the zoonotic potential, but, as illustrated by the last quotation presented above, 
bTB is generally no longer viewed as a public health threat due to the adequacy of state and food industry controls, particularly pasteurization.

This position contrasts markedly to the situation before the widespread adoption of pasteurization and statutory cattle testing programmes in the UK. For example, it has been estimated that over 800,000 people died from M. bovis infection in Great Britain between 1848 and 1960, and the zoonotic risk from M. bovis was the main driver for setting up statutory eradication programmes in Britain ${ }^{19,20}$. However, it could be argued that economic drivers for bTB control in cattle to protect export markets have always been more important in $\mathrm{NI}$ than the perception of zoonotic risk to humans ${ }^{10}$, as was suggested by several of the participants in this study who reasoned against attempting to eradicate bTB because it was a zoonosis.

The interviews were conducted between 2012 and 2013, and although this was several years ago, the bTB situation in cattle in NI has slightly worsened since then (herd incidence $7.32 \%$ in $2012,9.22 \%$ in 2018), and in the opinion of the author, the findings of the interviews are still as valid and relevant to consider today. While one must be cautious about generalizing the results of this study across all cattle farmers and livestock veterinarians in $\mathrm{NI}$ (and other high bTB incidence regions of the UK), the findings are nonetheless likely to be indicative of what the wider population believes about the risk of zoonotic TB in the twenty-first century when living with, and trying to eradicate, disease from an endemically infected national herd. As with other risks to health which become commonplace through habitual exposure (such as smoking-induced cancer ${ }^{21}$ ), risk can be neglected and largely ignored, and complacency often predominates, as was noted by several of the veterinarians interviewed. This case study and its findings suggest that there 
needs to be a change in attitude and practice by stakeholders towards the occupational and public health risks of $M$. bovis, even in developed countries with ongoing bTB eradication programmes, for the following reasons.

First, recent history demonstrates that there should not be complacency about the potential for M. bovis to infect and cause morbidity in humans in the UK and Ireland. Reported cases in the literature demonstrate risks to humans in the British Isles from multiple sources. For example, siblings living on a dairy farm in Gloucestershire, England were found to have the same strain of $M$. bovis as reactor cattle on the farm. It was noted that the male sibling could have acquired infection through restraining diseased cattle by the nostrils for veterinary examination ${ }^{22}$. Five from six family members on a dairy farm in the Republic of Ireland became positive to the Mantoux test after drinking unpasteurized milk on their farm, which had 26 bTB-positive cattle, including a cow with tuberculous mastitis ${ }^{23}$. A cluster of 6 human cases was discovered in the Midlands of England, all of whom had social links, and human-to-human transmission was hypothesized ${ }^{24}$. A veterinary nurse was found to have the same strain of $M$. bovis as her pet dog in south-west England, and she had prior exposure to cattle on farms assisting veterinarians with tuberculin testing ${ }^{25}$. These examples illustrate that while clinical TB caused by $M$. bovis is uncommon in humans, it is not entirely unusual, and should remain a differential for physicians treating TB patients, especially those who have contact with animals or drink unpasteurized milk.

Second, with a media-reported increased trend towards drinking unpasteurized bovine milk in the UK, coinciding with high incidence of bTB in parts of the UK in cattle herds, there could be a future increase in zoonotic infections by that route. Davidson et al. ${ }^{26}$, in a recent analysis of M. bovis cases in England, Wales and NI between 2002 and 2014 suggest that 
drinking unpasteurized milk was the most common source of infection in that period, and hypothesize that changing patterns of consumer behaviour could have contributed to the small increase in cases found in their analysis. The authors note that 'the effects of current unpasteurized milk consumption may not be observed for many years.' On a similar vein, Magnus ${ }^{27}$ warned many years ago that 'even if cattle tuberculosis is eradicated in a country, one has to reckon that the human population will bear traces from bovine tuberculous infection for several decades.'

Third, conclusions drawn from historic disease trends are no absolute guarantee of future trends. While national statistics show a low prevalence of $M$. bovis infection in humans amongst clinical cases in the UK, the relatively high burden of cattle infection seen in parts of the UK mean that comparatively more people have been exposed to $M$. bovis infection in the past two decades than in the period 1970 to the late 1990s. This was a period when bTB incidence in cattle in Great Britain was greatly reduced, and thought indeed to have been largely eradicated apart from small pockets of persistent infection in the south-west of England. NI has had a much more endemic situation for longer ${ }^{10}$, with presumably more human exposure, and the possibility of latent infection of with reactivation in old age, as has already been demonstrated in studies in the UK, must not be discounted ${ }^{28}$. Torres-Gonzalez et al. ${ }^{29}$, for example, found a high prevalence of latently infected dairy farm and abattoir workers in a high bTB cattle prevalence district of Mexico associated with occupational exposure. The factors affecting latency, and reversion to active disease, are complex and poorly understood for $\mathrm{TB}^{30,31}$, reducing our capabilities to project future infection outcomes. Neither should there be assumptions that $M$. bovis could not in future emerge as a more virulent pathogen than to date through the emergence of new strains, or the 
possibility that newly emerging co-infections or co-morbidities such as diabetes mellitus could not change the epidemiology and pathophysiology of $M$. bovis infection in humans, making it a more prevalent and fearsome proposition. This phenomenon, for example, is already seen with HIV-infected patients concurrently infected with $M$. bovis, which is a significant problem ${ }^{5}$. Despite its variable and disputed effectiveness in humans ${ }^{32}$, those who mentioned BCG vaccine generally expressed great faith in its ability to protect in the face of regular exposure to infected animals, although this confidence may be misplaced, especially with respect to adults Although BCG is effective at reducing the risk of children developing disseminated infection, it is largely ineffectual against pulmonary exposure in adults ${ }^{33}$, and protection can decrease over time ${ }^{34}$. It could therefore be argued that adults vaccinated as children may be at a similar risk of infection as non-vaccinates. Even so, if BCG has had some protective effect in the exposed population, as suggested by some of the interviewees, a generation of children in the UK are now growing up without any BCG vaccination, (unless classified to be in a high risk population and vaccinated as neonates) due to a change in UK government policy in $2005^{35}$.

Fourth, infections with $M$. bovis are often misdiagnosed, misclassified, and particularly awkward to treat in humans, and every possible precaution should be taken to avoid infection in the first place. As mentioned in the introduction, for those unfortunate enough to be infected with this pathogen, it is not an affliction to be dismissed or underestimated. Many cases of human TB may be wrongly classified as $M$. tuberculosis TB, even in developed countries, as they are clinically indistinguishable, and the bacterium may not be subject to molecular typing to differentiate ${ }^{36,37}$. M. bovis is more likely to cause extrapulmonary disease in humans than $M$. tuberculosis, making diagnosis more difficult and increasing the 
likelihood of not being reported ${ }^{30}$. It is also well recognized that $M$. bovis is resistant to pyrazinamide ${ }^{38}$, but patients may be initially started on this antimicrobial based on the assumption that $M$. tuberculosis is the pathogen causing the $\mathrm{TB}^{39}{ }^{40}$, leading to effective treatment delays and potentially increased morbidity and poorer outcomes. Indeed, although not associated specifically with treatment failures, an American study by Rodwell et al. ${ }^{41}$ found that people with $M$. bovis infection were 2.55 times $(p=0.01)$ more likely to die within the treatment period compared to those infected by M. tuberculosis.

For all of these reasons, it is a concerning situation that bTB as a zoonosis appears to be lightly regarded by some of the stakeholders most at risk of infection, and there is merit in re-iterating the call for action made by the WHO and others in their Roadmap for Zoonotic $T B^{6}$ : 'Zoonotic tuberculosis is not a new disease, but has long been neglected. The time is right for a bold and concerted effort to finally address the impact of Mycobacterium bovis infection on the health and well-being of people and animals.' Bovine TB is more than an economic or trade issue (while it is undoubtedly both); it is also a potential zoonosis which needs a renewed focus and drive to move closer towards eradication rather than the status quo ${ }^{10}$. Human and animal health can then be further improved for the mutual benefit of both.

\section{Conclusion}

Is the risk of $M$. bovis as an agent of zoonotic disease being underestimated in regions of endemic bTB infection within developed countries? With few clinical cases being discovered in the UK and other developed countries with advanced healthcare systems and concentrated animal surveillance, it may be that discourses around bTB harming humans are viewed as historical relics with little basis in the present or future. Or is the potentiality 
for an eruption of 'very, very sick' (Int A41) humans just a few cattle herd tests or a pattern of drinking raw milk away from becoming more real? Its harmful tendencies have been largely forgotten or downplayed by many on the frontline of bTB control in NI, and probably elsewhere in the British Isles, but every so often it reappears as a reminder that $M$. bovis can harm humans. As pointed out elsewhere, it may be 'time for a rethink [on bTB eradication] which takes the microbes themselves more seriously' ${ }^{42}$. That renewed emphasis from veterinarians and physicians may have an influence on how seriously M. bovis infection in cattle is viewed by farmers and their attitudes towards bTB eradication efforts.

\section{Acknowledgements}

The author acknowledges his grateful thanks to the Department of Agriculture, Environment and Rural Affairs in N. Ireland for the doctoral scholarship which funded this study, and the Dudley Stamp Memorial Trust for additional financial help with fieldwork expenses. The participation of the interviewees is most appreciated, as is the guidance of Prof. Peter Atkins, Prof. Gavin Bridge and Prof. Divya Tolia-Kelly while at Durham University. Part of this material was presented orally at the Acid Fast Club Summer meeting in the University of Oxford, July 2018, and the feedback from the meeting participants is gratefully acknowledged.

\section{Competing interests}

None declared. 


\section{References}

1. De la Rua-Domenech R. Human Mycobacterium bovis infection in the United Kingdom: incidence, risks, control measures and review of the zoonotic aspects of bovine tuberculosis. Tuberculosis 2006; 86: 77-109.

2. Vayr F, Martin-Blondel G, Savall F, et al. Occupational exposure to human Mycobacterium bovis infection: A systematic review. PLOS Neglected Diseases 2018; 12(1): e0006208.

3. Torgerson PR, Torgerson DJ. Public health and bovine tuberculosis: what's all the fuss about? Trends Microbiol 2010; 18: 67-72.

4. Olea-Popelka F, Muwonge A, Perera A, et al. Zoonotic tuberculosis in human beings caused by Mycobacterium bovis - a call for action. The Lancet Infectious Diseases 2017; 17(1): e21-e25.

5. Olea-Popelka F, Dean AS, Muwonge A, et al. Mycobacterium bovis as the causal agent of human tuberculosis: public health implications. In: Chambers M, Gordon S, Olea-Popelka F, Barrow P, eds. Bovine tuberculosis. Wallingford and Boston: CABI, 2018: 16-30.

6. World Health Organization (WHO), Food and Agriculture Organization of the United Nations (FAO) and World Organisation for Animal Health (OIE). 2017. Roadmap for zoonotic tuberculosis. (http://apps.who.int/iris/bitstream/handle/10665/259229/9789241513043eng. pdf;jsessionid=40F22EOC1COE02685328893312F7DDE9?sequence=1) (accessed 17 June 2019).

7. Funk S, Salathe M, Jansen VAA. Modelling the influence of human behaviour on the spread of infectious diseases: a review. Journal of the Royal Society Interface 2010; DOI: 10.1098/rsif.2010.0142. 
8. Lau JTF, Yang X, Pang E, et al. SARS-related perceptions in Hong Kong. Emerg Infect Dis 2005; 11: 417-424.

9. Joffe H. Public apprehension of emerging infectious diseases: are changes afoot? Public Understanding of Science 2011; 20: 446-460.

10. Robinson PA. A history of bovine tuberculosis eradication policy in Northern Ireland. Epidemiology and Infection 2015; 143: 3182-95.

11. Robinson PA. Farmers and bovine tuberculosis: Contextualising statutory disease control within everyday farming lives. Journal of Rural Studies 2017; 55: 168-180.

12. Department of Agriculture, Environment and Rural Affairs, N. Ireland. The Agricultural Census in Northern Ireland: Results for June 2018. Belfast: DAERA, 2019.

13. Department of Agriculture, Environment and Rural Affairs, N. Ireland. Tuberculosis statistics. (https://www.daera-

ni.gov.uk/sites/default/files/publications/daera/Tuberculosis\%20-

\%20internet\%20monthly\%20statistics\%20-\%20December\%202018.pdf ). (accessed 17 June 2019).

14. Curtis S, Gesler W, Smith G, et al. Approaches to sampling and case selection in qualitative research: Examples in the geography of health. Soc Sci Med 2000; 50: 10011014.

15. Robinson PA. Framing bovine tuberculosis: a 'political ecology of health' approach to circulation of knowledge(s) about animal disease control. The Geographical Journal 2017; 183: 285-294. 
16. Reilly LV. Human tuberculosis of bovine origin in Northern Ireland. Journal of Hygiene 1950; 48:464-471.

17. Public Health England. United Kingdom Mycobacterium bovis surveillance data tables.

Table 1: Number of people with M. bovis by country, UK 1999-2017.

(https://www.gov.uk/government/publications/mycobacterium-bovis-mbovis-tuberculosisannual-data). (accessed 17 June 2019).

18. Public Health Agency. Epidemiology of Tuberculosis in Northern Ireland: Annual Surveillance Report 2016. Belfast: Public Health Agency.

19. Atkins PJ. A history of uncertainty: Bovine tuberculosis in Britain 1850 to the present. Winchester: Winchester University Press, 2016.

20. Atkins PJ. The long genealogy of quality in the British drinking-milk sector. Hist Agrar 2017; 73: 35-58.

21. Heikkinen H, Patja K, Jallinoja P. Smokers' accounts on the health risks of smoking: Why is smoking not dangerous for me? Soc Sci Med 2010; 71: 877-883.

22. Smith RMM, Drobniewski F, Gibson A, et al. Mycobacterium bovis Infection, United Kingdom. Emerg Infect Dis 2004; 10: 539-541.

23. Doran P, Carson J, Costello E, et al. An outbreak of tuberculosis affecting cattle and people on an Irish dairy farm following the consumption of raw milk. Irish Vet J 2009; 62: 390-397. 
24. Evans JT, Smith EG, Banerjee A, et al. Cluster of human tuberculosis caused by Mycobacterium bovis: evidence for person-to-person transmission in the UK. Lancet 2007; 369: 1270-1276.

25. Shrikrishna D, de la Rua-Domenech R, Smith NH, et al. Human and canine pulmonary Mycobacterium bovis infection in the same household: re-emergence of an old zoonotic threat? Thorax 2009; 64: 89-91.

26. Davidson JA, Loutet MG, O'Connor C, et al. Epidemiology of Mycobacterium bovis disease in humans in England, Wales, and Northern Ireland, 2002-2014. Emerg Infect Dis 2017; 23: 377-386.

27. Magnus K. Epidemiological basis of tuberculosis eradication: 3. Risk of pulmonary tuberculosis after human and bovine infection. B World Health Organ 1966; 35: 483-508.

28. Mandal S, Bradshaw L, Anderson LF, et al. Investigating transmission of Mycobacterium bovis in the United Kingdom in 2005 to 2008. J Clin Microbiol 2011; 49: 1943-1950.

29. Torres-Gonzalez P, Soberanis-Ramos O, Martinez-Gamboa A, et al. Prevalence of latent and active tuberculosis among dairy farm workers exposed to cattle infected by Mycobacterium bovis. PLOS Neglect Trop D 2013; 7: e2177.

30. Salgame P, Geadas C, Collins L, et al. Latent tuberculosis infection - revisiting and revising concepts. Tuberculosis 2015; 95: 373-384.

31. Turner RD, Chiu C, Churchyard GJ, et al. Tuberculosis infectiousness and host susceptibility. J Infect Dis 2017; 216: S636-643 
32. Evans TG, Brennan MJ, Barker L, et al. Preventive vaccines for tuberculosis. Vaccine 2013; 31S: B223-B226.

33. Kaufmann SHE. Novel tuberculosis vaccination strategies based on understanding the immune response. J Intern Med 2010; 267: 337-353.

34. Sterne JAC, Rodriguez LC, Guedes IN. Does the efficacy of BCG decline with time since vaccination? Int J Tuberc Lung D 1998; 2: 200-207.

35. Fine P. Stopping routine vaccination for tuberculosis in schools. Brit Med J 2005; 331: 647-648.

36. Hlavsa MC, Moonan PK, Cowan LS, et al. Human tuberculosis due to Mycobacterium bovis in the United States, 1995-2005. Clin Infect Dis 2008; 47: 168-175.

37. Lombardi G, Botti I, Pacciarini ML, et al. Five-year surveillance of human tuberculosis caused by Mycobacterium bovis in Bologna, Italy: an underestimated problem. Epidemiol Infect 2017; 145: 3035-3039.

38. De Jong BC, Onipede A, Pym AS, et al. Does resistance to pyrazinamide accurately indicate the presence of Mycobacterium bovis? J Clin Microbiol 2005; 43: 3530-3532.

39. Corcoran JP, Hallifax RJ, Bettinson HV, et al. Tuberculous pleuritis secondary to Mycobacterium bovis in a veterinarian. Clin Respir J 2016; 10: 500-503.

40. Moloney DP, Chawke L, Crowley MT, et al. Fluctuating hypercalcaemia caused by cavitary Mycobacterium bovis pulmonary infection. BMJ Case Reports 2018; doi:10.1136/bcr-2017-222351. 
41. Rodwell TC, Moore M, Moser KS, et al. Tuberculosis from Mycobacterium bovis in binational communities, United States. Emerg Infect Dis 2008; 14: 909-916.

42. Robinson PA. Performativity and a microbe: Exploring Mycobacterium bovis and the political ecologies of bovine tuberculosis. BioSocieties 2019; 14: 179-204. 